\title{
Gamma-glutamyl transpeptidase deficiency
}

INSERM

\section{Source}

INSERM. (1999). Orphanet: an online rare disease and orphan drug data base. Gammaglutamyl transpeptidase deficiency. ORPHA:33573

A disorder that is characterized by increased glutathione concentration in the plasma and urine. 